\title{
Dinâmica familiar em situação de nascimento e puerpério
}

\section{Familiar dynamics in situation of birth and puerperal}

\author{
Dinámica familiar en situation de nacimiento y puerperio
}

\author{
Cleusa Alves Martins', Karina Machado Siqueira", Maria Antonieta Rubio Tyrrell"', Maria Alves \\ Barbosa $^{\prime v}$, Sílvia Maria Soares Carvalho ${ }^{\vee}$, Luzinéia Vieira dos Santosv
}

\section{RESUMO}

As mudanças ocorridas durante os períodos de nascimento e puerpério podem interferir significativamente na dinâmica familiar. A formação de uma rede de apoio pelo grupo familiar pode ser extremamente benéfica, tanto para a puérpera quanto para os demais membros que vivenciam de forma mais próxima o nascimento da criança. Este estudo objetivou identificar a participação efetiva dos membros da família nos cuidados a puérpera e ao recémnascido após alta hospitalar e analisar a dinâmica da família durante esse período. Pesquisa qualitativa, realizada entre abril e maio de 2004, junto a mães no período puerperal e suas famílias, assistidas pela Estratégia Saúde da Família, na Região Leste de Goiânia-GO. Durante a análise, identificaram-se três categorias temáticas: A dinâmica familiar; $O$ suporte assistencial à mulher; $A$ experiência do nascimento. Verificou-se que a assistência a puérpera e ao recém-nascido é compartilhada pelos membros do clã familiar. As avós são pessoas significativas no cuidado, labor doméstico e suporte financeiro. A pequena participação ou ausência paterna está associada ao seu trabalho. O suporte profissional foi importante para as famílias, nos levando a uma postura reflexiva quanto à necessidade de se desenvolver ações integradas na assistência à saúde da mulher no período pré-natal e puerperal.

Palavras chave: Saúde da Família; Serviços de saúde; Enfermagem Obstétrica.

\section{ABSTRACT}

The changes happened during the first periods from birth and postpartum period can interfere significantly in the family dynamics. The formation of a support net for the family group can be extremely beneficial, so much for the puerperal as for the other members that live in a closer way the child's birth. This study aimed to identify the effective participation of the family members in the puerperal cares and to
}

the baby after hospital rise and to analyze the dynamics of the family during this period. Qualitative research, made among April and May in 2004, with mothers on postpartum period and her family, taken care by the Health of the Family Program on the East Region of the city of Goiânia-GO. During the analysis three thematic categories were identified: The familiar dynamics; the assistance support to the woman; the experience of the birth. It was verified that the assistance to puerperal and to the baby is shared by the members of the familiar clan. The grandmothers are significant people in the care, domestic work and financial support. The small participation or paternal absence is associated with their work. The professional support was important for the families, in leading to a reflexive posture how much to the necessity of developing actions integrated in the assistance to the health of the woman in the prenatal and puerperal period.

Key words: Family Health; Health Services; Obstetrical Nursing.

\footnotetext{
1 Trabalho de Final de Curso - Residência em Saúde da Família da Faculdade de Enfermagem da Universidade Federal de Goiás - FEN-UFG/MS/SMS, financiado pelo REFORSUS/MS. Pesquisa vinculada ao Núcleo de Estudos em Paradigmas Assistenciais e Terapias Alternativas (NEPATA) da Faculdade de Enfermagem da Universidade Federal de Goiás.

' Enfermeira Obstetra. Doutora em Enfermagem. Professora Adjunta da Faculdade de Enfermagem da Universidade Federal de Goiás - FEN/UFG. Goiânia-GO. E-mail: cleusa@fen.ufg.br

"Enfermeira. Mestre em Enfermagem. Professora Assistente da Faculdade de Enfermagem da Universidade Federal de Goiás - FEN/UFG. E-mail: karinams@fen.ufg.br

III Enfermeira. Doutora em Enfermagem. Professora Titular Diretora da Escola de Enfermagem Anna Nery da Universidade Federal do Rio de Janeiro - EEAN/UFRJ. Email: direcao@eean.ufrj.br

IV Enfermeira. Doutora em Enfermagem. Professora Adjunta da Faculdade de Enfermagem da Universidade Federal de Goiás - FEN/UFG. E-mail: maria.malves@gmail.com

$\checkmark$ Enfermeira do Programa de Saúde da Família de GoiâniaGO. Especialista em Saúde da Família.
} 
Martins CA, Siqueira KM, MAR, Barbosa MA, Carvalho SMS, Santos LV. Dinâmica familiar em situação de nascimento e puerpério. Rev. Eletr. Enf. [Internet]. 2008;10(4):1015-25. Available from: http://www.fen.ufg. br/revista/v10/n4/v10n4a13.htm.

\section{RESUMEN}

Los cambios durante los periodos del nacimiento y puerperio pueden interferir significativamente en la dinámica familiar. La formación de una red de apoyo por el grupo puede ser sumamente beneficiosa, tanta para la puérpera cuanto a los otros miembros que viven de una manera más íntima el nacimiento del niño. Este estudio tuvo como objetivo identificar la participación efectiva de la familia en los cuidados a la puérpera y al bebé posteriormente al alta del hospital y analizar la dinámica de la familia, durante este periodo. Pesquisa cualitativa, realizada entre abril e mayo de 2004, junto a madres en el periodo de puerperio y sus familias, atendidas por el Programa de Salud de la Familia, en la Región Este de la ciudad de Goiânia-GO. Durante el análisis han sido

\section{NTRODUÇÃO}

Este estudo trata da dinâmica de famílias que vivenciam situações de nascimento e puerpério, eventos que podem interferir significativamente na estrutura familiar, envolvendo mudanças na vida de seus membros, devido à necessidade de cuidados específicos a puérpera e ao recém-nascido.

A chegada de um novo membro à família pode gerar um aumento na tensão familiar, pois traz consigo a necessidade de uma reformulação nos papéis e nas regras de funcionamento familiar. O nascimento de uma criança constitui-se um acontecimento nodal no ciclo de vida familiar, passível de influenciar, de formas bastante diversas, o equilíbrio eventualmente desfrutado pela família( ${ }^{(1)}$.

Atualmente, no município de Goiânia, dentre as ações para a operacionalização da assistência qualificada à família na rede pública de saúde - SUS, destaca-se a Estratégia Saúde da Família - ESF, que visa prioridades na atuação de prevenção e controle das situações de risco numa abordagem assistencial humanizada e integral à família - enfoque que fortalece a compreensão dos diferentes meios culturais de desenvolvimento humano, intimamente ligado à realidade social no processo saúde/doença, e constitui importantes fatores na determinação de procedimentos no campo assistencial da saúde, um direito de cidadania da população brasileira.

A consolidação plena do dispositivo identificados tres categorías temáticas: La dinámica familiar; La ayuda asistencial a la mujer; La experiencia del nacimiento. He sido verificado que la ayuda al puérpera y al bebé es compartida por los miembros del clan familiar. Las abuelas son personas significativas en el cuidado, trabajo doméstico y ayuda financiera. La pequeña participación o la ausencia paternal se asocian a su trabajo. La ayuda profesional he sido importante para las familias, nos conduciendo a una postura reflexiva cuánto a la necesidad de desarrollar acciones integradas en la asistencia a la salud de la mujer en el período prenatal y puerperal.

Palabras clave: Salud de la Familia; Servicios de salud; Enfermería Obstétrica.

constitucional da Lei Orgânica da Saúde - LOS, Lei no 8.080 de 19 de setembro de 1990, regulamentou o Sistema Único de Saúde - SUS e estabeleceu os princípios da universalidade, eqüidade, integralidade de atenção à saúde do indivíduo, por meio da descentralização dos serviços como forma de operacionalizar os avanços das ações, em nível de promoção, prevenção, recuperação e reabilitação(2).

Nessa perspectiva, o Ministério da Saúde (MS) desenvolveu o Programa Saúde da Família, atualmente denominado Estratégia Saúde da Família, como forma de otimização de recursos estabelecidos por Normas Operacionais da Assistência à Saúde - NOAS / SUS 01/2001 - que determinam a regionalização da assistência de média e alta complexidade, no âmbito do SUS, garantindo assim, o acesso aos serviços. Desse modo, essa estratégia se configura um novo modelo assistencial de saúde pública, tendo a família como foco central do cuidado.

Em função do período puerperal, tanto a mulher quanto os demais membros que vivenciam o nascimento da criança, sofrem um grande desgaste físico e psíquico, sendo extremamente benéfica e importante a formação de uma rede de apoio familiar.

É importante compreender a saúde a partir das relações entre os membros da família, sua estrutura e sua dinâmica, fatores que podem funcionar como facilitadores ou dificultadores na determinação da saúde de 
Martins CA, Siqueira KM, MAR, Barbosa MA, Carvalho SMS, Santos LV. Dinâmica familiar em situação de nascimento e

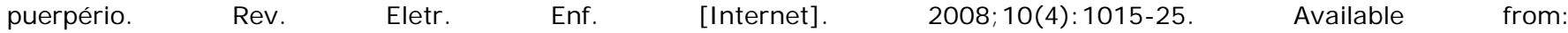
http://www.fen.ufg. br/revista/v10/n4/v10n4a13.htm.

seus membros. Os papéis familiares são constituídos a partir da função de cada membro, de acordo com a posição que ocupa nos subsistemas conjugal, parental, fraterno e filial. Desse modo a integração familiar possibilita atuação grupal para fins comuns, cujo intuito é promover o desenvolvimento saudável dos membros familiares. Ou seja, quando cada membro conhece e desempenha seu papel específico, a família torna-se facilitadora de saúde física e emocional de seus membros ${ }^{(3)}$.

Nessa linha de pensamento, a família e seu espaço social são eleitos como foco da atenção à saúde. Família pode ser conceituada como um sistema ou uma unidade cujos membros podem ou não estar relacionados ou viver juntos, pode conter ou não crianças sendo elas de um único pai ou não; consiste em unidade de proteção, alimentação e socialização(4).

Assim, em que pese os aspectos sociais, considera-se que eventos marcantes do cotidiano como casamento, divórcio, mortes e nascimentos causam impacto no arranjo familiar. E, neste sentido, um episódio que chama a atenção é a intensificação das intervenções de ajuda no grupo familiar quando ocorre o nascimento de uma criança e a mãe se encontra no período puerperal.

No que se refere ao período de adaptação da mãe com o recém-nascido no ambiente extra-uterino, os cuidados com a higiene, coto umbilical, amamentação, e ainda, as alterações físicas e psíquicas experimentadas pela puérpera são situações que podem causar ansiedade e dificuldades no dia a dia da mãe que vivencia essa realidade, e potencialmente, representar um fator estressante para os demais membros da família.

Deste modo, assistir a família em situação de puerpério e nascimento como uma unidade de cuidado, implica em conhecer como cada família cuida e identifica suas forças, dificuldades e seus esforços para partilhar responsabilidades ${ }^{(4)}$.

Nesta perspectiva, este estudo apresenta reflexões acerca da assistência à mulher no período gravídico-puerperal no seu núcleo familiar e oferece subsídios teóricos às instituições formadoras de profissionais na área da saúde para o desenvolvimento da assistência humanizada às famílias, em especial, em situação de nascimento e puerpério.

A partir deste contexto, nossas inquietações emergiram questões que nortearam este estudo, quais sejam: Qual a inserção de familiares na prestação de cuidados a puérpera e ao recém-nascido? Como as famílias estão vivenciando o período puerperal e a chegada da criança? Que transformações ocorreram na família com a chegada da mãe e seu bebê, após alta hospitalar?

Assim, os objetivos deste estudo foram: identificar a participação efetiva da família e equipe da Estratégia Saúde da Família na assistência à mãe e ao recém-nascido no domicílio e analisar a dinâmica familiar em situação de nascimento e puerpério, após alta hospitalar.

\section{METODOLOGI A}

Para investigar a dinâmica familiar optouse pela pesquisa qualitativa, que segundo Minayo ${ }^{(5)}$, confere potencialidade para apreender e analisar aspectos do desenvolvimento social, por refletir as preocupações e os interesses de determinados grupos e classes sociais.

Este estudo foi desenvolvido na comunidade dos bairros J ardim Dom Fernando I e Jardim Dom Fernando II (área 508), da Região Leste do município de Goiânia-GO, onde residem cerca de 1.100 famílias cadastradas no Programa de Saúde da Família. Estes bairros possuem rede de água, energia elétrica, esgoto sanitário, ruas asfaltadas e serviço de coleta de lixo.

Os dados foram coletados nos meses de abril e maio de 2004, atendendo os critérios da Resolução 196/96 ${ }^{(6)}$, e normas do Comitê de Ética em Pesquisa Médica Humana e Animal do Hospital de Clínicas da Universidade Federal de Goiás, protocolo de aprovação CEPMHA/HC/UFG no $023 / 2004$.

Foram adotados como critérios de exclusão: ausência das famílias no domicílio no momento das visitas e família cuja mulher gravidez resultou em óbito fetal ou o recémnascido permaneceu hospitalizado, Portanto, os sujeitos constituíram-se de cinco famílias que 
Martins CA, Siqueira KM, MAR, Barbosa MA, Carvalho SMS, Santos LV. Dinâmica familiar em situação de nascimento e

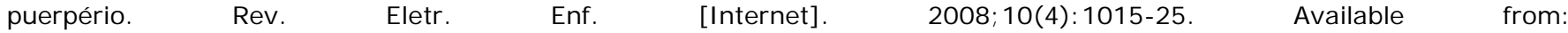
http://www.fen.ufg. br/revista/v10/n4/v10n4a13.htm.

residiam na área e concordaram em participar.

Foram entrevistadas: cinco mães, três pais, três avós, quatro cunhadas e uma sobrinha. Duas famílias residiam no mesmo lote dos seus pais, enquanto, dois casais compartilham moradia com seus pais, ou seja, moram com a família da puérpera ou do companheiro. Todas as puérperas residiam maritalmente com seus companheiros na ocasião do estudo, sendo que três casais vivenciavam a experiência do primeiro filho.

As pesquisadoras realizavam visitas às famílias quando a mãe e criança retornavam ao domicílio após alta hospitalar. As enfermeiras faziam o acolhimento, prestavam cuidados às puérperas e orientavam as mãe quanto os cuidados ao recém-nascido e ao auto-cuidado, ocasião em que as convidavam a participar do estudo e agendava a entrevista, em horário adequado para congregar maior número de pessoas que compartilhava o episódio. As entrevistas ocorreram na segunda visita, até o 16 o dia de puerpério, quando as pesquisadoras fizeram observação da dinâmica familiar e dos cuidados, seguindo roteiro semi-estruturado. As entrevistas foram gravadas e posteriormente transcritas integralmente. Para resguardar a identidade dos depoentes, nos trechos de relatos descritos foram atribuídos aos mesmos, códigos formados por números de 1 a 5 e por letras: mãe - M; pai - P; avó - A; cunhada - C.

Os dados foram analisados segundo a técnica de "Análise de Conteúdo", tipo Modalidade Temática ${ }^{(5)}$. "O tema é a unidade de significação que se liberta naturalmente de um texto analisado segundo critérios relativos à teoria que serve de guia à leitura"(7). Esta modalidade de análise foi considerada adequada porque permitiu a identificação de três categorias temáticas, as quais receberam as seguintes denominações: A dinâmica familiar; $O$ suporte assistencial à mulher; e A experiência do nascimento.

\section{RESULTADOS E DISCUSSÃO}

A análise os dados evidenciaram que as famílias vivenciam a situação nascimento de uma criança e a mulher no puerpério como sendo um evento compartilhado por outros membros do clã, ao mesmo tempo em que criam um vínculo e compromisso nos cuidados à mãe e ao recém-nascido.

Embora toda família possua capacidade de encontrar suas respostas e sempre busque uma forma de rearranjo para continuar visando seus ideais, toda vivência altera o seu funcionamento na busca de respostas quando se depara com dificuldades que interferem neste processo, então, no momento em que expressam suas necessidades precisam de apoio, de serem ouvidas e cuidadas ${ }^{(8)}$.

No presente estudo, as puérperas tinham idade entre 19 e 23 anos; seus companheiros entre 21 e 23 anos, sendo um com idade superior a 30 anos. Apenas um dos companheiros era comerciante e possuía curso superior, os demais trabalhavam como servente de pedreiro, comerciário, vigilante e gari. Dentre as puérperas, duas exerciam atividades remuneradas, uma era comerciante e outra comerciária, as demais exerciam atividades do lar.

\section{A dinâmica familiar}

O nascimento provocou a mobilização dos familiares para apoiar a puérpera na lida doméstica e nos cuidados com 0 bebê. Observamos que esse apoio também se deu no aspecto financeiro e iniciou mesmo antes do nascimento. O nascimento, como um evento social, também facultou a aproximação ou reaproximação dos familiares, promovendo além do apoio, a oportunidade para passear, rever filhos e parentes, tal como revelam as falas: Foi difícil demais pra mim sair, o povo perguntava assim: você vai mesmo cuidar dela e deixar sua mãe? Eu disse: oh! gente, é difícil eu deixar minha mãe nesse estado, mas a minha filha é minha filha (A4). Ela mora em Goianésia (...) ela ficou de um dia para o outro, só para conhecer a neném (M3). Melhor pra passear, pra cuidar do bebê (A1). Depois foi minha cunhada que veio e ficou morando comigo (M5).

Em alguns casos, os familiares afastaramse dos afazeres em seus lares, provocando uma série de angústias e dificuldades. A necessidade de uma reformulação nos papéis e nas regras de funcionamento familiar devido à chegada de um novo membro, pode gerar um aumento na 
Martins CA, Siqueira KM, MAR, Barbosa MA, Carvalho SMS, Santos LV. Dinâmica familiar em situação de nascimento e

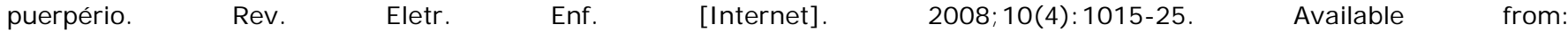
http://www.fen.ufg. br/revista/v10/n4/v10n4a13.htm.

tensão familiar. Constitui-se um momento marcante no desenvolvimento da família, podendo trazer um desequilíbrio ao sistema como um todo, para cada um de seus membros e para as relações estabelecidas entre eles ${ }^{(1)}$.

A gravidez e o nascimento propiciaram a troca de conhecimentos entre familiares, pois a necessidade de cuidar bem do filho levou a mãe a buscar experiências de outras pessoas da sua convivência: família, amigos, vizinhança. Essa interação social e o modo de se organizarem permitiram à puérpera a formação de conceitos para desenvolver suas atividades como mãe. Nesse momento de rearranjo, a mulher convive com orientações do senso comum oriundas dos familiares, desse modo, os profissionais da área de saúde devem lançar mão de estratégias que permitam utilizar os conhecimentos adquiridos nessa interação como forma de contribuir no cuidado adequado à mãe e ao recém-nascido:

Até na hora de sair para o hospital eu expliquei. Eu disse: olha, é assim, agüenta a mão mais um pouquinho que aí vem as contrações. Fui alertando ela...(A4). Quando ela chora, eu chego assim e aí se ela estiver espremendo eu vejo que é cólica... eu sei quando ela quer mamar (M3). Eu achei interessante porque o jeito deu dar banho nos meus meninos não era o mesmo jeito que ela (profissional de saúde) ensinou... (A1).

Os discursos também foram bastante esclarecedores sobre o posicionamento das famílias quando ocorre o nascimento de uma criança, os membros mais experientes tornamse cuidadores. Essa conduta é explicável, em virtude que a puérpera nos primeiros dias, apresenta dificuldades em cuidar e amamentar o filho:

Fica acordada, espremendo, aí tem vez que ela chora, aí eu faço massagem na barriguinha, igual minha mãe me ensinou (M3); ... aí eu por minha experiência, eu disse para as minhas meninas, eu cozinho canjica com leite, com côco, é muito bom pra aumentar o leite (...), aquela marmelada, canjica, cuscuz com queijo (A4); Quando eu criei meus filhos eu dava um chazinho de erva-doce, de puejo (...) adoçado com mel de abelha, enquanto o leite não vem (A4).

A tradição familiar é manifestada nos cuidados à saúde das crianças. As falas revelaram que a família distingue suas práticas daquelas orientadas pelo profissional de saúde e também reforçou a valorização da família como integrante do seu próprio cuidar.

O discurso dos participantes corrobora com a literatura, pois práticas populares como chás caseiros, benzeduras e utilização de diversas substâncias no curativo do coto umbilical são difundidos entre diferentes gerações e continuam a fazer parte do cotidiano de mães ao cuidarem de seus filhos ${ }^{(9)}$.

Neste estudo, ficou claro o interesse da família em apoiar e a orientação aos pais nos cuidados com o bebê, em algumas famílias um membro significativo se apoderou da responsabilidade de iniciar os pais nos cuidados com o filho. As falas revelaram este apoio aos pais quando eles não conseguiam resolver algumas situações, como cólicas, choro noturno, dentre outros, como declarado nas falas:

Aí ela ajudava quando estava com colicazinha, que ele estava chorando, que ninguém sabia o que ele tinha, a avó tomava conta.... (C2). Quem dá banho é minha mãe e minha sogra (M1); Só dei um bainho nele até agora. É muito novinho, molinho, tenho medo... (M1); ... antes do umbigo cair, eu nem mexo com aquilo, morro de medo do umbigo arrancar, só jogava álcool (M3).

Mães e pais consideraram importante a atuação dos avós no apoio psicológico, além da contribuição com suas experiências de vida para resolver situações difíceis ${ }^{(10)}$. Os depoimentos mostraram que as avós quase sempre realizavam o banho do bebê e o curativo no coto umbilical e quando não estavam presentes as tias e vizinhas assumiam essa tarefa, pois, ao olhar da mãe, esse procedimento exige habilidades de pessoas mais experientes.

Nos cuidados domésticos, outros familiares também exerceram papel importante durante o puerpério, em virtude de algumas limitações físicas que as puérperas apresentaram:

A minha sobrinha, cunhada, uma vem arruma a casa, a outra lava roupa (M4); A minha vizinha ali (...) aqui da frente, ela que vem limpar a casa e cuidar das coisas pra mim (M5).

Atualmente, conforme identificado em 
Martins CA, Siqueira KM, MAR, Barbosa MA, Carvalho SMS, Santos LV. Dinâmica familiar em situação de nascimento e

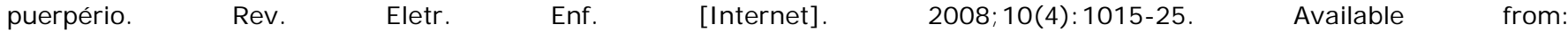
http://www.fen.ufg.br/revista/v10/n4/v10n4a13.htm.

nossos resultados, o pai participa no cuidado ao filho e também auxilia a companheira cuidando dos outros filhos. Em algumas famílias esse pai se mostrou um cuidador importante, especialmente, nos primeiros dias de nascimento: Eu que acordo ela (esposa) todo dia (...) aí ela levanta, acende a luz, pega o bebê. Daí quando ele começa a dar trabalho demais eu já levanto e tenho que conversar com ele (...) fico com ele um pouco... (P2); Foi muito bom trocar a fralda, eu gosto do meu filho cheirosinho (P2).

Em outro estudo, quando questionadas em relação ao apoio recebido do companheiro, as mães destacaram sua satisfação pela participação destes nos cuidados diários dos filhos $^{(11)}$.

A participação do pai nos cuidados prestados ao filho é importante para o desenvolvimento adequado da criança e na construção do vínculo paterno. Entretanto, alguns pais justificaram sua pequena e discreta participação nos cuidados ao filho em virtude do seu cansaço e para não ausentarem do seu trabalho, conforme declararam:

Eu não, não escuto, fico cansado demais, tenho sono pesado, nunca acordei (P3); Às vezes sim e às vezes não, porque meu trabalho é a noite (...) E de noite, porque que ela tem um pouquinho de preguiça de acordar, eu tenho que ir até o berço pegar o neném, levar pra ela dar mamar...(P5); Ele tá dormindo em quarto separado. Porque minha mãe ia chegar aí ele achou que ela dormindo comigo fosse melhor (M1).

Alguns autores tratam da reconfiguração dos papéis nos núcleos familiares a partir do nascimento de filhos, momento em que se criam novos laços: parental, mãe-filho, paifilho, e os cônjuges organizam-se para lidar com novos papéis, assim como os membros da respectiva família de origem ${ }^{(1-3,11)}$.

\section{O suporte assistencial à mulher}

Desde junho de 2000, o Ministério da Saúde instituiu o Programa de Humanização no Pré-Natal e Nascimento (PHPN), que apresenta em sua formulação os seguintes objetivos: reduzir as altas taxas de morbimortalidade materna e perinatal, ampliar o acesso ao pré- natal, estabelecer critérios para qualificar as consultas e promover o vínculo entre a assistência ambulatorial e o parto ${ }^{(12)}$.

Apesar da existência de políticas públicas de saúde específicas, como o PHPN e a Estratégia Saúde da Família, as famílias demonstraram insatisfação com os atendimentos durante o acompanhamento de pré-natal. As falas referem que as consultas são muito rápidas, centradas apenas na barriga da mulher, sem haver uma interação entre a cliente e familiares com os profissionais. Essa distância parece contribuir para participação efetiva da mulher e familiares no processo de gestação e nascimento, contrariando toda a proposta de humanização da assistência materna e neonatal:

Chega lá você só responde o que te pergunta e o que você tá sentindo, a consulta é muito rápido. Vai naquele assunto o tempo todo e esquece dos outros. A maioria das vezes é assim (C2); Desde quando comecei o pré-natal eu não gostei. É só a minha barriga...(M2); Tão rápido a ultrassonografia, o seu bebê como é que ele tá, mais aí eles falam assim: Tudo bem, tudo bem. Acho que deveria ter uma orientação maior (C2).

As falas revelam que a assistência prénatal não atende às expectativas das gestantes e suas famílias. Em estudo sobre avaliação preliminar dos indicadores gerados após dois anos da instituição do PHPN, evidenciou-se que apenas para pequena parcela das mulheres cadastradas houve registro do cumprimento integral dos critérios. A maioria das mulheres recebeu assistência desarticulada e parcial; menos de $25 \%$ das mulheres cadastradas teve seis ou mais consultas pré-natal ${ }^{(13)}$.

Dentre as puérperas, quatro realizaram parto vaginal e uma se submeteu a cesareana. Para algumas mulheres, o nascimento e o puerpério foram vivenciados de maneira natural. Outras mães referiram situações de dor e desconforto, principalmente nos primeiros dias, citando a episiotomia, o ferimento cirúrgico da cesareana e a contração uterina estimulada com a amamentação:

Para mim foi normal (M1); Nossa, foi agoniante, doía pra caramba, era difícil demais pra sentar. Nos primeiros dias foi difícil, senti muita cólica, 
Martins CA, Siqueira KM, MAR, Barbosa MA, Carvalho SMS, Santos LV. Dinâmica familiar em situação de nascimento e

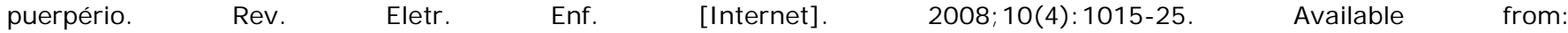
http://www.fen.ufg. br/revista/v10/n4/v10n4a13.htm.

os pontos, muita cólica na hora que a neném mamava (M3); Cada gravidez é diferente e cada nascimento também foi diferente. Pior foi o meu corte que a gente não pode ficar levantando, andando (M5).

Assistir a família em situação de puerpério e nascimento como uma unidade de cuidado, implica em conhecer como cada família cuida e identifica suas forças, dificuldades e seus esforços para partilhar responsabilidades ${ }^{(4)}$. Ao contrário do pré-natal, a assistência no puerpério constituiu apoio emocional e instrumental para as famílias, que acreditam ser positivo o apoio recebido pelo serviço de saúde durante este período. Referiram que os conhecimentos discutidos acrescentam muito aos já possuíam:

A orientação da enfermeira é muito boa, por mais que a gente sabe, nunca sabe tudo(P2); Fez muita diferença, tirou algumas dúvidas, me ensinou a limpar o umbigo (M3); Foi bom demais, sobre as massagens que você explicou, sobre o tipo de agasalhar ele na hora que ele tiver chorando (A4).

Algumas mães, pais e familiares fizeram referências que evidenciam a importância do acompanhamento do enfermeiro no puerpério, período em que mulher se encontra muito vulnerável, pois efetivamente vivencia o exercício da maternidade, enquanto ocorrem as profundas modificações fisiológicas e psíquicas.

As informações expressas pelas puérperas evidenciam a importância do vínculo profissional-cliente. $O$ estabelecimento de relações efetivas pode proporcionar liberdade à mulher e permitir um importante canal de expressão. Estar bem informada pode contribui substancialmente para a resolução de dúvidas, e pode minimizar o sentimento de insegurança, angústia e anseios, vivenciados nesta fase da vida da mulher ${ }^{(14)}$.

Nesse contexto, o domicílio torna-se um importante cenário para extensão do cuidado de enfermagem, uma vez que as puérperas, na maioria das vezes, não se sentem preparadas e seguras para o desempenho de seu novo papel. As visitas domiciliares podem aumentar a segurança e a autoconfiança da mãe ao enfrentarem o puerpério ${ }^{(15)}$.

\section{A experiência do nascimento}

No que diz respeito ao vivenciar o nascimento do filho, alguns pontos foram ressaltados durante as falas dos entrevistados como a amamentação, o impacto do nascimento no orçamento financeiro familiar, o cuidado ao recém-nascido, a influência do bebê no comportamento dos membros familiares e a recompensa aos pais.

A chegada do bebê provoca realização e estreita relação no seio familiar, traz expectativas ao casal e têm significados especiais à família:

Foi uma maravilha, o primeiro netinho, estou muito feliz (A1); Tem sido ótimo, com muita alegria. Quando avisou que ela já tinha ganhado neném, ficou tudo alegre, a família toda. O telefone toda hora tocava ... (A4); Pra mim foi uma maravilha, porque desde quando começou eu já esperava por um homem, fez a ultrasonografia e deu homem (P2).

A gestação e o nascimento constituem fases de mudanças, com transformações e incertezas que acompanham a aquisição de novos papéis e responsabilidades antes inexistentes na família, incluindo-se as relacionadas com outros filhos, com a casa e com os demais membros da família(16).

O nascimento também se revela como uma possibilidade de romper a rotina das famílias, que passaram a conviver com situações não pensadas durante a gestação, o parto e nascimento. O choro do bebê geralmente é uma incógnita nos primeiros dias, acordar durante a noite para acolher as necessidades do bebê foi tido como desafio a ser enfrentado, alterando a rotina e a estrutura familiar anterior ao nascimento, situações às vezes contraditórias que carecem da assistência de enfermagem. As falas expressam as adversidades desse momento:

Só não esperava que fosse tão difícil ser mãe (...). Ele chora, ela não sabe o que ele quer, tem que adivinhar, você queria mais não sabia que não vinha com manual, tudo é novo (C2); Tem vez que ela passa a noite em claro, só cochila, acorda, e eu junto dela...(M3); Eu pensava que não ia ser tão difícil, não ia ser essa canseira dele acordar toda noite, toda hora acorda. Pensava que ele ia dormir, ficar 
Martins CA, Siqueira KM, MAR, Barbosa MA, Carvalho SMS, Santos LV. Dinâmica familiar em situação de nascimento e

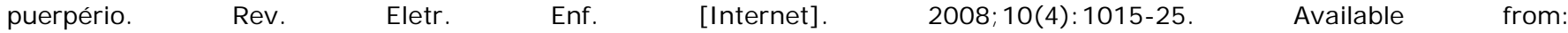
http://www.fen.ufg. br/revista/v10/n4/v10n4a13.htm.

tranqüilo, apesar dele ser bom, mais não deixa de acordar de noite...(P2).

Nesse sentido, torna-se oportuno destacar que o exercício da maternidade deve ser compreendido como um processo social e culturalmente construído e que, por isso, necessita ser aprendido no dia-a-dia, por meio de ensinamentos, de vivências e de ajuda ${ }^{(14)}$.

No que diz respeito ao aleitamento materno, diferentes experiências foram registradas pelas mães. Expressaram como sendo um momento agradável, mas também haviam dificuldades relacionadas ao nervosismo do bebê, ao processo de lactação, ingurgitamento mamário, fissura mamilar, entre outros:

Tá sendo bom (amamentar), tirando o nervosismo dele quando pega, quando tira. Tira da boca dele, ele fica nervoso, aí não quer pegar mais (...) Nossa senhora, foi terrível, meu seio empedrou todinho (...) o bico é invertido(M2); Eu não estava tendo leite, aí eu comecei a ficar nervosa, chorei (M4); Na hora de amamentar também eu sofri muito porque meu primeiro menino eu dei duas vezes mam porque meu leite secou, então eu nunca amamentei. Agora eu estou a amamentando, então é mais complicado porque o bico do meu peito rachou, doía demais...(M5).

Os resultados mostraram que as mães e avós consideraram-se responsáveis pelo suprimento alimentar do bebê e acolhimento em relação ao choro. Se por um lado, isso demonstra o vínculo já existente, por outro, expressa também a responsabilização do cuidado:

Pensei: como será meu filho se eu não der, não tiver leite, o que é que vai ser dele. Eu pensei que ele não ia criar (M4); Porque ele vai ficar lá chorando, eu não vou conseguir dormir (...). Eu acho que a solução vai ser eu (E4); Fiquei muito apavorada (com a dificuldade em aleitar) principalmente por causa do marido dela ... (A4).

Neste estudo, a amamentação, especialmente nos primeiros dias, mobilizou familiares e causou ansiedade. $O$ fato de o bebê ficar chorando e não conseguir boa pega ao seio leva os pais a acreditarem que ele está com fome, levando-os a introduzir o leite artificial, esta situação foi compartilhada com profissionais de saúde, sendo importante observar as necessidades nutricionais do bebê, bem como merece atenção o ingurgitamento mamário caso necessário ordenhar o leite para evitar desenvolvimento de processos inflamatórios nas mamas e, ainda conviver com o período determinante para o aleitamento materno exclusivo:

Toda vez que ele ia mamar, ela (a mãe) só pegava o bebê, a gente tinha que pegar o seio e apertar assim e segurar pra ele dá conta de mamar... (C2); Mandaram eu botar a boca no peito da mulher e lá vou eu, meter a boca pra tirar o leite. Era só sangue na minha boca. Falei: não, pára, não quero. $\mathrm{E}$ aí mandaram eu comprar a bombinha eu tive de comprar (P2); Teve um dia que ele correu lá no supermercado, comprou uma lata de leite Nan, chegou e, prepara aí uma chuquinha pra dá a ele...(A4).

A fala de uma avó cita a amamentação da criança por outra nutriz - não a mãe - revelando o desconhecimento da família quanto ao risco de transmissão de doenças:

Minha nora chegou, estava criando e ajudou (...) Chegou na hora certa, ela deu mamar a ele... (A4).

A apreensão das puérperas e familiares em relação ao aleitamento materno reflete a deficiência de informações obtidas durante o pré-natal sobre as particularidades do período puerperal, especialmente a amamentação. Em outro estudo, realizado em Fortaleza-CE, as puérperas referem que as dúvidas e a insegurança quanto à prática da amamentação se estenderam durante a internação no sistema de alojamento conjunto e persistiram após a alta hospitalar ${ }^{(15)}$.

É evidente que o cuidado necessita ter continuidade após o parto e o domicílio pode tornar-se um espaço importante para a educação e assistência à saúde ${ }^{(15)}$. Frente a tantas vulnerabilidades vividas pelas mulheres e seus familiares no período puerperal, os profissionais que atuam na atenção básica, em especial aqueles vinculados à Estratégia Saúde da Família, necessitam assumir seu relevante papel na atenção materno-infantil.

A assistência à mulher no período puerperal deve englobar os aspectos biológicos, 
Martins CA, Siqueira KM, MAR, Barbosa MA, Carvalho SMS, Santos LV. Dinâmica familiar em situação de nascimento e

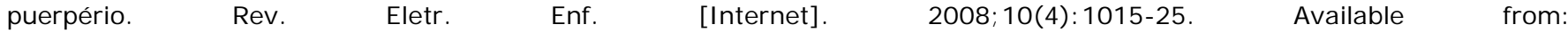
http://www.fen.ufg.br/revista/v10/n4/v10n4a13.htm.

físicos e emocionais, e os profissionais de saúde podem colaborar de maneira efetiva na escolha de mecanismos adaptativos e defensivos com o intuito de superar os momentos de crise ${ }^{(14)}$.

Outro aspecto ressaltado neste estudo foi o impacto do nascimento no orçamento financeiro familiar, o qual foi destacado nas falas ao discutirem as atividades ocupacionais e profissionais dos provedores dessas famílias. Historicamente, se construiu o papel que os pais desempenham no núcleo familiar - o homem como provedor e a mulher como cuidadora/educadora dos filhos. Dois depoimentos de pais revelam essas situações:

Não era o que eu pensava não. $A$ responsabilidade é muita. Nunca achei que ia gastar tanto. A fralda vai acabando, o cotonete (...) Quando acaba, não acaba só o cotonete, é o lenço, quando não é o lenço é uma pomada, é uma receita de médiço e vai indo. Mas não deixa de ser bom (P2); Sente mais um entrando na família, eu acho muito bom, batalhar e conseguir o melhor pra eles, dois não é fácil, tem que cuidar(...)Fiquei desempregado... (P5).

A responsabilização do provimento financeiro e das necessidades materiais dos filhos pode assustar os homens, fato este mais intenso na chegada do primeiro filho ${ }^{(17)}$. Estudo revela que alguns pais de crianças pequenas consideraram que o apoio financeiro é mais importante do que o apoio psicológico recebido dos familiares ${ }^{(10)}$.

Ainda em relação à questão financeira, estudo evidencia que a precária condição socioeconômica da puérpera constitui-se um fator que influencia no aparecimento de depressão pós parto ${ }^{(18)}$.

A influência do nascimento no comportamento dos membros familiares foi referida em relação a atitudes dos outros filhos. Ao sentiram a chegada de outra criança em casa apresentaram mudança de comportamento como ciúme, ficando mais tempo em casa junto a mãe, houve um relato contrário que não sentia diferença na rotina, as alterações ocorridas foram qualificadas por eles como normais:

Os meninos saem menos, estão mais carinhosos, pararam mais de sair pra rua por causa dele $(\mathrm{M} 1) ; \ldots$ ele fica bastante enciumado, é complicado nesse termo também" (M5); Não mudou a rotina, até agora, não sei pra frente, mas até agora não.. (P5).

A chegada de um novo bebê, além de afetar o comportamento dos outros irmãos, também pode levar a mudanças na relação dos genitores com os filhos. Estas mudanças podem ocorrer tanto em um nível comportamental (qualidade, freqüência e padrões relativos de interação) quanto em um nível mais abstrato, incluindo as percepções e emoções dos envolvidos ${ }^{(11)}$.

A sobreposição de papéis com o nascimento as mães iniciam o processo de adaptação às demandas requeridas pelo bebê, outros filhos e cuidados domésticos. Por ocasião deste estudo todas mães estavam convivendo com companheiro, constituindo uma possibilidade de compartilhar as atividades domésticas e os cuidados ao recém-nato. Embora, cotidianamente, em nossa prática observamos que muitas mães criam seus filhos sem a presença do companheiro, sendo elas próprias provedoras do lar. Algumas falas exprimem a sobrecarga de trabalho e a preocupação das mães em deixar suas crianças, após licença a maternidade:

Só fica mais difícil pra fazer as coisas quando o neném chora, dar banho toma mais tempo. Nada, não durmo durante o dia também tem o outro filho (M3); ...porque meu primeiro foi menino homem, aí eu tive mais ajuda, agora da minha menina já não tenho tanta ajuda... (M5); ...tenho plano de voltar a trabalhar, o que vai acontecer, será se vai ter o mesmo cuidado que eu tenho $(. .$.$) tem que ser pessoa de confiança$ (M1); ... depois de quarenta dias vou voltar pra sorveteria de novo e cuidar do bebê, da casa e da sorveteria, as três coisas ao mesmo tempo (M4).

Os filhos, especialmente os recémnascidos demandam dedicação e cuidado. Geralmente, as mães, adequando-se às necessidades, sobrepõem funções na divisão de seu tempo como cuidadoras dos filhos, da casa e trabalhadora. Ao assumir essas responsabilidades, a mulher sente-se sobrecarregada, sendo que essa sobrecarga pode refletir em insegurança, cansaço e perda da liberdade ${ }^{(14)}$. 
Martins CA, Siqueira KM, MAR, Barbosa MA, Carvalho SMS, Santos LV. Dinâmica familiar em situação de nascimento e

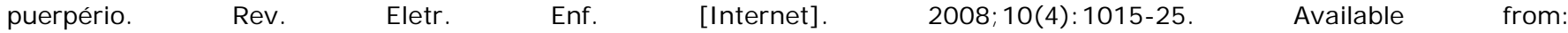
http://www.fen.ufg. br/revista/v10/n4/v10n4a13.htm.

Todos integrantes da família, inclusive o pai, podem contribuir com as tarefas a fim de evitar sobrecarga sobre uma só pessoa. Devese valorizar um modelo de paternidade mais envolvida, em sua intensidade afetiva e solidária, modificando qualitativamente o significado da paternidade. Nesse sentido, além do direito de expressar sua afetividade, o pai assume o dever de ser um pai participativo nos cuidados do filho ${ }^{(16)}$.

\section{CONSI DERAÇÕES FI NAIS}

A análise dos discursos mostrou que o evento puerperal é compartilhado pelos membros do clã familiar como forma de cooperar na assistência a puérpera e ao recémnascido. $O$ envolvimento dos familiares apareceu no sentido de apoiar a mãe, desde a gestação até o puerpério.

As avós se revelaram como pessoas significativas, tanto por seus conhecimentos e suas experiências, como contribuindo financeiramente e ajudando nas atividades domésticas e nos cuidados relacionados à higiene do bebê. Além das avós, as cunhadas e vizinhas também foram citadas nestes cuidados. Geralmente, as mães não realizavam cuidados como banho e curativo do coto umbilical quando as avós estavam presentes.

Se por um lado, o nascimento representou a realização do sonho da maternidade e paternidade, por outro, significou o rompimento das rotinas anteriores. Puérperas e familiares relataram essa ambigüidade de sentimentos, pois referem experimentar momentos difíceis e angustiantes decorrentes da assistência aos filhos e atividades do lar, mas ao mesmo tempo vivenciaram momentos de alívio e alegria.

A troca de conhecimentos - inerentes à cultura, costumes e práticas familiares - se mostrou como forma de contribuição para a adaptação dos pais aos novos papéis. Verificouse que as famílias lançam mão de várias práticas domésticas e crenças populares utilizadas como alternativas de tratamento e cuidado com a mãe e recém-nascido.

Em decorrência do parto e nascimento criaram-se outras demandas de tarefas, as quais famílias procuraram se adaptar. O suporte profissional apresentou-se como algo importante na vida das famílias, nos levando a uma postura reflexiva quanto à necessidade de se desenvolver ações de forma integrada, fundamentais na assistência à saúde da mulher no período pré-natal e puerperal.

Ficou evidente que o atendimento à saúde da mulher no período gravídico-puerperal implica, sem dúvida, o resgate de intervenções não restrito apenas à esfera ambulatorial e hospitalar. Especialmente aos profissionais que atuam na Estratégia Saúde da Família, fica o desafio de se desenvolver ações efetivas na atenção básica, considerando o domicílio como um espaço importante para a integração e implementação de ações junto às gestantes, puérperas, seus familiares e comunidade.

\section{REFERÊNCI AS}

1. Pereira CRR, Piccinini CA. O impacto da gestação do segundo filho na dinâmica familiar. Estud. psicol. (Campinas). 2007; 24(3): 385-95.

2. Martins CA. O Programa de Assistência Integral à Saúde da Mulher (PAISM), em Goiânia: a (des)institucionalização da consulta de enfermagem no pré-natal [thesis]. Rio de Janeiro: Escola de Enfermagem Anna Nery /UFRJ ; 2001.

3. Féres-Carneiro T. Família e saúde mental. Psic.: Teor. e Pesq. 1992; 8 Suppl: 485-93.

4. Angelo $M$, Bousso RS. Fundamentos da assistência à família em saúde. In: Ministério da Saúde. Instituto para o Desenvolvimento da Saúde. Manual de Enfermagem. Brasília (Brasil): Ministério da Saúde; 2001.

5. Minayo MCS. O Desafio do conhecimento: pesquisa qualitativa em saúde. 8th ed. São Paulo/Rio de Janeiro: HUCITEC/ABRASCO; 2003.

6. Ministério da Saúde; Conselho Nacional de Saúde. Resolução № 196/96 - Normas regulamentadoras de pesquisa envolvendo seres humanos. Brasília (Brasil): Ministério da Saúde; 1996.

7. Bardin L. Análise de Conteúdo. Lisboa: Edições 70; 1977.

8. Wernet $M$, Ângelo $M$. Mobilizando-se para a família: dando um novo sentido à família e ao cuidar. Rev. Esc. Enferm. USP. 2003; 37(1): 1925. 
Martins CA, Siqueira KM, MAR, Barbosa MA, Carvalho SMS, Santos LV. Dinâmica familiar em situação de nascimento e puerpério. Rev. Eletr. Enf. [Internet]. 2008;10(4):1015-25. Available from: http://www. fen.ufg. br/revista/v10/n4/v10n4a13.htm.

9. Souza MA, Melo MB, Silveira Júnior RS, Barbosa MA, Siqueira KM, Martins CA, et al. Práticas populares adotadas nos cuidados em saúde da criança. Rev. enferm. UERJ. 2006; 14(4): 512-7.

10. Dessen MA, Braz MP. Rede social de apoio durante transições familiares decorrentes do nascimento de filhos. Psic.: Teor. e Pesq. 2000; 16(3): 221-31.

11. Piccinini CA, Pereira CRR, Marin AH, Lopes RCS, Tudge J. O nascimento do segundo filho e as relações familiares. Psic.: Teor. e Pesq. 2007; 23(3): 253-61.

12. Ministério da Saúde. Programa de humanização no pré-natal e nascimento. Brasília (Brasil): Secretaria de Políticas de Saúde; 2000.

13. Serruya SJ, Lago TG, Cecatti JG. Avaliação preliminar do Programa de Humanização no Pré-Natal e Nascimento no Brasil. Rev. Bras. Ginecol. Obstet. 2004;26(7):517-25.

14. Merighi MAB, Gonçalves R, Rodrigues IG. Vivenciando $\mathrm{o}$ período puerperal: uma abordagem compreensiva da Fenomenologia Social. Rev. Bras. Enferm. 2006; 59(6): 775-9.

15. Rodrigues DP, Fernandes AFC, Silva RM, Pereira MS. O domicílio como espaço educativo para o autocuidado de puérperas: binômio mãefilho. Texto contexto-enferm. 2006; 15(2):27786.

16. Freitas WMF, Coelho EAC, Silva ATMC. Sentir-se pai: a vivência masculina sob o olhar de gênero. Cad. Saúde Pública. 2007;23(1): 137-45.

17. Maldonado MT, Dickstein J, Nahoum JC. Nós estamos grávidos. 11th ed. São Paulo: Saraiva; 2000.

18. Moraes IGS, Pinheiro RT, Silva RA, Hortac BL, Sousa PLR, Faria AD. Prevalência da depressão pós-parto e fatores associados. Rev. Saúde Públ. 2006; 40(1):65-70.

Artigo recebido em 14.03.07.

Aprovado para publicação em 31.12.08. 